\title{
APPROXIMATION OF IMMUNE RESPONSE ABILITIES IN SALMONID GILLS USING THE RTGILL-W1 CELL LINE AS AN IN VITRO MODEL
}

\author{
Claudio Alvarez ${ }^{1,2 *}$, Paula Santana ${ }^{1,2 *}$, Francisco Donoso ${ }^{1 *}$, Felipe Ramírez ${ }^{1 *}$, Jimena \\ Cortés $^{1 *}$, Fanny Guzmán ${ }^{2 *}$, Rafael da $\operatorname{Rosa}^{3 *} \&$ Luis Mercado ${ }^{1,2}, * \S$
}

${ }^{1}$ Grupo de Marcadores Inmunológicos, Laboratorio de Genética e Inmunología Molecular, Instituto de Biología. Pontificia Universidad Católica de Valparaíso, Valparaíso, Chile. ${ }^{2}$ Núcleo Biotecnológico de Curauma (NBC). Pontificia Universidad Católica de Valparaíso, Valparaíso, Chile.

${ }^{3}$ Laboratório de Imunologia Aplicada à Aquicultura. Universidade Federal de Santa Catarina, Florianópolis. Brasil.

Teleost fish gills represent a considerable exchange surface with the external environment. Our group has previously presented evidence regarding the expression and detection of regulatory and effector molecules of the immune response system in salmonid gills. This observation is supported by increased macrophage infiltration in this organ. However, it is probable that gill epithelial tissue also possesses immunomodulatory abilities. The RTgill-W1 cell line presents an epithelial morphology and forms tight monolayer sheets, thereby representing a key model for understanding how fish gills are able to identify the presence of microorganisms and trigger the immune response. The aim of this study was to determine if the epithelial cells of salmonid gills are able to detect pathogen associated molecular patterns (PAMPS) through intracellular receptors, using the activation of intracellular signaling intermediaries to secrete immunomodulatory cytokines. The RTgill-W1 line expressed TNF $\alpha$, IL-1 $\beta$, and type 1 IFN in response to stimulation with LPS and Poly I:C. Knockdown of the NOD-like receptor (NLRC5) with siRNA (siNLRC5) decreased the expression of IFN- $\alpha / \beta$ in RTgill-W1 cells treated with Poly I:C. In turn, knockdown of the TRIM protein (siTRIM3) in cells treated with LPS resulted in the downregulation of TNF $\alpha$ and IL-1 $\beta$. Additionally, the cell line responded to rIFN- $\gamma$ stimulation by upregulating TRIM8, a facilitator of the JAK/STAT pathway. These data provide interesting evidence regarding the immune function of the gill epithelium. This studied was financed through Proyecto FONDECYT N 1140797

KEYWORDS: Fish innate immunity, NLR, TRIM proteins, fish cytokines, IFN- $\gamma$ 
*These authors contributed equally to this work.

${ }^{\S}$ Corresponding author. Tel.: +56 322274860

E-mail address: luis.mercado@pucv.cl 